\title{
Should We Aim to Create a Perfect Healthy Utopia? Discussions of Ethical Issues Surrounding the World of Project Itoh's Harmony
}

\author{
Atsushi Asai ${ }^{1}$ (D) $\cdot$ Taketoshi Okita $^{1} \cdot$ Motoki Ohnishi $^{2} \cdot$ Seiji Bito $^{3}$
}

Received: 1 October 2019 / Accepted: 22 September 2020 / Published online: 13 October 2020

(c) Springer Nature B.V. 2020

\begin{abstract}
To consider whether or not we should aim to create a perfect healthy utopia on Earth, we focus on the SF novel Harmony (2008), written by Japanese writer Project Ito, and analyze various issues in the world established in the novel from a bioethical standpoint. In the world depicted in Harmony, preserving health and life is a top priority. Super-medicine is realized through highly advanced medical technologies. Citizens in Harmony are required to strictly control themselves to achieve perfect health and must always disclose their health information to the public and continuously prove their health. From a bioethical standpoint, the world in Harmony is governed by a "healthy longevity supremacy" principle, with being healthy equated to being good and right. Privacy no longer exists, as it is perceived ethical for citizens to openly communicate health-related information to establish one's credibility. Moreover, there is no room for self-determination concerning healthcare because medical interventions and care are completely routinized, automated, centralized, and instantly provided. This is a situation where the community exhibits extremely powerful and effective paternalism. One can argue that healthy longevity is highly preferred. But is it right to aim for a perfectly healthy society at all costs? Should we sacrifice freedom, privacy, vivid feelings, and personal dignity to achieve such a world? In our view, the answer is no, as this would require the loss of many essential values. We conclude by proposing an alternative governing principle for future healthcare, and refer to it as the "do-everything-in-moderation" principle.
\end{abstract}

Keywords Project itoh $\cdot$ Science fiction $\cdot$ Super-medicine $\cdot$ Health $\cdot$ Unethical human experiment $\cdot$ Moderation

Atsushi Asai

aasai@med.tohoku.ac.jp

Extended author information available on the last page of the article 


\section{Introduction}

A great work of science fiction (SF) can present us vivid images of possible futures as well as bring to light serious issues, allowing us to learn valuable lessons by depicting human relations, new cultural tendencies, and novel relationships between human beings, science, and technology. Here we pick up the masterpiece SF novel Harmony, written by Japanese writer Project Itoh in 2008, and consider the various ethical issues involving the world depicted in the novel, as well as its ending.

Harmony won the 40th Seiun (Galaxy) Award and the 30th Japan SF Award in 2009, both of which are awarded to the best SF novels in Japan. The novel was translated into English in 2010 (by Alexander O. Smith, 2010, San Francisco, Haikasoru), and the English version was awarded the Philip K Dick Special Award the same year. Project Itoh wrote Harmony while being hospitalized for lung cancer treatment, and passed away at the early age of 34 in March 2009.

Present society aims for a future in which healthy longevity is achieved through advanced medicine and science, as well as technology such as artificial intelligence (AI), information communication technology (ICT), and nanotechnology. In our view, we are edging closer to the world depicted in Harmony (hereafter, "Harmony's World"). With the rapid development of AI, ICT, and other relevant medical technologies in recent years, it is now much easier to imagine that the healthcare system and way of living depicted in Harmony's World could be realized in the near future. In addition, health-consciousness among people is becoming universal, and this has led to strong anxiety about health as well as fear of aging and death (Asai et al. 2019). In this context, we believe we can gain insight into important lessons about ethical, social, and psychological issues that could arise in a healthy longevity utopia achieved by super-medicine by analyzing Harmony's World.

In the sections that follow, we will introduce the protagonists of the story, provide an overview of social and healthcare systems including those pertaining to mental health, and summarize the story. We will also present a brief history of medical progress as well as look closer into current medical technologies and healthcare services closely related to Harmony's World. We will then analyze various ethical issues that arise in Harmony's World. Finally, to conclude, we propose appropriate attitudes toward health and healthcare and argue that a perfect healthy utopia should not be a goal. To the best of our knowledge, no academic paper has been published in Japan or overseas that analyzes Harmony from the bioethical standpoint. We focus mainly on issues concerning health, healthcare, and medical technologies, but will not discuss in detail the definition, theory, or function of consciousness, a major theme of the novel. Page numbers in parentheses in quoted text indicate the corresponding page numbers of the English version of Harmony. In addition, before the conclusions of this paper, we will introduce several relevant SF stories to compare with Harmony and to illustrate possible consequences of future developments described in these literary works. 


\section{Harmony's World as Depicted by Project Itoh}

Tuan Kirie, a 28-year-old woman, is the main character of Harmony. This work is told in the first person of Tuan. It is the year 2073, and Tuan is a World Health Organization (WHO) monitoring officer who protects people's right to life. Her job is to ensure that society guarantees healthy and humane lives for its members and to intervene when necessary. Tuan describes her mission as follows:

We are basically a flag-waving troop of diplomats-cum-peacekeepers charged with the protection of life everywhere...[T]o check whether they were ensuring their populace a lifestyle that was sufficiently healthy and human. (p. 41).

She was ordered to temporarily return to Japan by her boss after a certain incident. Shortly afterwards, more than 6000 people around the world attempted suicide simultaneously, and 2796 people, including one of Tuan's best friends from high school, were successful in the attempt. An unidentified criminal declares to all citizens in the world:

Within the next week, I want you each to kill at least one other person... Those who are unable or unwilling to perform this small task will die. (p. 144).

The main story in Harmony concerns Tuan Kirie's investigation into the cause of the multiple suicides and identification of the person who issued the one-man-one-kill order. Harmony's World is governed by an ideology referred to as Lifeism (Project Itoh's coinage). Lifeism is explained as being a politically enacted policy or tendency to view the preservation of health as the community's highest responsibility (p. 42). Harmony's World consists of communities which include people who have reached a consensus on a particular medical system and these medical conclaves are referred to as administrations (Project Itoh's coinage) (p. 34). The medical conclaves (or administrations) have successfully realized super-medicine that uses advanced medical technologies including AI, ICT, and nanotechnology. Based on the welfare societies of the twenty-first century, this means the inclusion at adulthood of a constant internal monitoring network through a device called WatchMe, the establishment of a high-volume medical consumer system with affordable medicine and medical activities, and the provision of proper nutrition and lifestyle advice designed to mitigate predicted lifestyle-related illnesses. These activities are seen as the basic minimum conditions for human dignity (p. 42).

Community groups cover $80 \%$ of the world (p. 174), but some areas do not belong to a medical consensus community. For these $20 \%$, super-medicine has nothing to do with citizens' lives. Those who live outside medical conclaves are just like usthey catch colds, get headaches, get cancer, and die around the age of sixty or seventy (p. 173). On the other hand, in medical conclaves, all people install WatchMe by injection into their bodies when the body finishes growing, i.e., when they become adults. WatchMe constantly monitors the level of RNA transcription errors and immunological consistency in human blood at the molecular level. Based on data sent from WatchMe, a little pharmaceutical factory in every household called Medicare (personal medical drug purification system) synthesizes substances called 
Medicule (Project Itoh's coinage) needed to eliminate pathogenic substances in the blood, and sends Medicule, in a matter of milliseconds, to the area where the abnormality occurred at pinpoint and eliminates substances harmful to the human body. Medicule can also issue a warning via measuring homeostasis in the body (p. 32).

As a result, swarms of medicines have essentially eliminated most diseases off the face of the planet (p. 31). Medicare performs autonomous, automatic, and instant medical interventions. Medical treatments are nearly perfect and citizens' health management is almost completely realized. Interestingly, healthcare professionals do not appear in the novel at all. A healthy longevity world has been established where no one is ill, the elderly are extremely active and healthy, and no one dies except in accidents or due to senility. In addition, each person's life is designed together with a health consultant. It is the extreme health-conscious society (p. 112).

In Harmony's World, there are no interventions based on scientific technologies such as nanotechnology, let alone devices for monitoring the brains of community members. WatchMe is not designed to directly monitor mental activities, nor is Medicule able to pass through the blood-brain barrier. Behavior modification is attempted by request for self-restraint via traditional educational methods and social pressure. Promotion of healthy behavior, and improvement of the environment by eliminating factors that could adversely affect mental and physical health, also lead people to live a healthy life. Good health and health efforts are awarded high social assessment points, further motivating people to make efforts toward self-restraint. WatchMe warns people when a disturbance in the autonomic nervous system is detected and blocks harmful information, which also helps maintain peace of mind. Children and young adults who cannot tolerate health education or the demand to live a public life attempt suicide or self-harm, as discussed later in Sect. 5, unrelated to the aforementioned incident by the unidentified criminal. Suicide that occurs frequently in this society is interpreted as a rebellion against controlled mental health by individuals who suffer from feelings of disillusionment and despair toward society, as well as hopeless, disconsolate feelings and a sense of entrapment.

The above-mentioned medical conclaves were born after reflecting on a frightening history. In 2019, a riot in the United States led to ethnic slaughter, and nuclear warheads spread around the world during the ensuing turmoil. This led to frequent nuclear terrorism, and radiation led to the development of cancer in many people. In addition, an unknown virus was generated due to the radiation, and many people succumbed to it and fell ill. This event is referred to as "Maelstrom," meaning "the great disaster." The World in the face of an imminent health crisis established medical conclaves overnight. Now, most parts of the world are free from chaos, savage, and slaughter, and a utopian world of peace, healthy longevity, and love has been realized (p. 23).

As it becomes apparent during the course of the story, Harmony's World adopts an oligarchy political system; $80 \%$ of humans are basically under the watchful eye of a select group of people (p. 139). This group refers to itself as the Next-Generation Human Behavior Monitoring Group. Group members (i.e., leading senior citizens of medical conclaves, highest authorities of the medical industrial complex, and some scholars and scientists) have no intention of exploiting members of medical conclaves and created the healthy longevity society purely based on good intentions. 
They are solely dedicated to preventing the return of "Maelstrom," and have the noble intentions of ensuring healthy longevity and world peace. No malice exits and the rulers remain concerned that all it would take is one mishap for cancers and viruses to return (p. 114).

\section{Brief History of Medical Progress, and Current Medical Technologies and Healthcare Services Related to Harmony's World}

We present here a brief overview of the history of medicine and medical development which are relevant to Harmony's World. Progress in medicine has provided solutions to various diseases including infectious diseases, genetic disorders, malignant tumors, and cerebrovascular disorders, and brought about mental stability to many people. All of these medical advances are cornerstones of the medical technologies used in Harmony's World. In fact, a comparison between modern-day medical care that has evolved over the past 10 years to that of Harmony's World reveals a number of similarities. For example, wearable wireless devices that measure and display vital signs, steps, calorie consumption, and other variables have been in widespread use, with smartphones providing health guidance. Continuous blood glucose monitoring devices have also been put into practical use. The use of "Digital Pills" started, in which a patient's medication status and physical condition are monitored by a sensor patch and ingestible sensor and sent to a central server and physicians, and improvement in medication adherence is attempted via guidance feedback. Digital medicine includes a wide range of devices, such as temperature-monitoring foot mats capable of automatically detecting diabetic foot ulcers or clinically validated smartphone apps for smoking cessation combined with video tutorials and nicotine replacement therapy (Ohta 2018; Martani et al. 2020; Biesen et al. 2019).

Behaviors of members of the public are monitored, recorded, and aggregated for the purpose of preventing the spread of infectious diseases using smartphone location information and surveillance cameras. Anti-cancer therapy with a drug delivery system using nanomolecules created by nanotechnology, micro-sample diagnosis, medical treatment by nano-robots, diagnosis/drug selection/prediction of disease onset based on genome analysis, gene manipulation by CRISPR/Cas9 genome editing in fertilized eggs, and organ regeneration by regenerative medicine technology have also begun (Sekai-Cyoukan 2020; Kanaya and Ichikawa 2016; Kobayashi 2016; Johnston et al. 2018; Sunshine and Paller 2019; King and Bishop 2019; Itai 2019); Medicule and genetic-level repairs of abnormalities described in Harmony' World are beginning to be realized.

The development of diagnostic systems using AI deep learning which had made a substantial breakthrough in the past decade is another active area of research. Medical AI is used to carry out pathological diagnosis, diagnostic imaging, endoscopic diagnosis, diagnosis of and critical care for rare and intractable diseases, prediction of patient prognosis, and big data management. AI robots also provide nursing care. Direct-to-Consumer medicine using a digital healthcare application has also been put into motion (Susskind and Susskind 2015; Kirinuki-sokuho 2019). 
Many countries guarantee affordable healthcare and good access to medical care through universal health care systems. In Japan, the Health Promotion Act (2002) states that citizens are responsible for health promotion, as well as local governments and the state, thereby setting the stage to support healthy lifestyles and promote behavior modifications. Simultaneously, the Act prescribes environmental maintenance to prevent passive smoking in society (Okita et al. 2017). Thus, we would argue that Harmony's World is an SF story depicting a "Brave Healthy World" and can also be regarded as a speculative fiction about a health promoting society.

\section{Social Consequences of the Healthy Longevity Supremacy Principle in Harmony's World}

As mentioned above, medical conclaves in Harmony's World covers $80 \%$ of the world population and exclusively aim to promote healthy longevity and life retention. Harmony's World devotes itself to realizing the health-supremacy principle and healthism, and this leads to various problematic issues, which are discussed in detail below (Table 1). We can gain insight into important lessons about ethical, social, and psychological issues of our future world with strong health orientation by analyzing Harmony's World in detail. First, the extreme healthoriented and health-conscious society has given rise to health worship. In this world, healthy longevity is considered more important than anything else. Health

Table 1 Problematic issues in Harmony's World, and the questionable means to sustain it

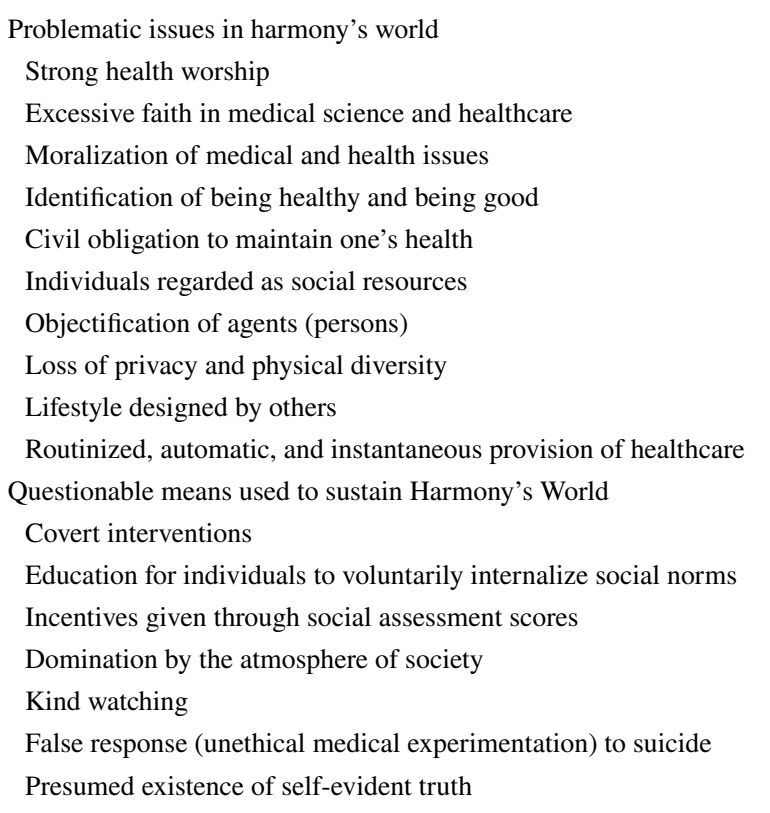


has super-value and dictates the way people live and how they think. Thus, being healthy becomes a moral obligation of all community members. It is a world where being healthy and being ethical are synonymous.

Miach Mihie, one of Tuan's best friends who hated Harmony's World, plays an important role. She states:

The value we call health is trampling us over everything else. It means that the flood is coming. We are about to drown. (p. 127).

Another one of Tuan's colleagues, who is critical of the excessive health-oriented society, mentions:

Since we are both here on business, we don't have to worry about oil or cholesterol or any moral concerns. Let's eat! (p. 222).

Here, we note that cholesterol and ethical concerns are referred to in the same dimension. Taking cholesterol would be considered unethical in the context of a non-work situation. Also, a goody-goody woman in the community who claims that coffee addiction is a serious problem and should be banned mentions:

I was just wondering if there isn't a moral problem with the taking of caffeine. (p. 146).

Tuan describes Harmony's World as follows:

Plague, booze, and smokes - loot too good to pass up. You could not find any of these things in Japan, a nation obsessed with health, or anywhere else under admedistration rule, for that matter. All these vices, things which had gone more or less ignored in the past, had been carved in a list of sins by the all-powerful hand of medicine, and one by one, they had been purged form a society. (p. 12).

She also mentions:

The invention of medicines had put the human body and moral precept side by side on the same lab table... The program took care of the signal sent form the body and transmitted morals in return. The moral code over 80 percent of the people in the world had taken for their own. (p. 103).

Substance intake that leads to poor health is a sin in Harmony's World. Issues surrounding alcohol, smoking, and coffee suggest that health-related perfectionism is an endless slippery slope. In Harmony's World, medicine is the subject of people's faith. In this regard, Tuan states:

Our gods, Asklepios and Hippocrates, watched closely over us, the 'medicine people' and in their name we built temples to clinical medicine and shock down nearly every disease ever known. Our faith was such that we would continue striking them down, and so the medicine people who would never be abandoned by their gods. (p. 28). 
The propensity to avoid caffeine and animal fats, and taking only healthy food, can be considered orthorexia nervosa, an obsession with eating only healthily or an obsessional adherence to a clean, pure, and healthy diet (McCartney 2016). One commentator argues that individuals with orthorexia consider their eating styles to be virtuous and wholesome, citing ethical reasons for their eating practices, and they may even proudly discuss their dietary practices because they believe their eating behaviors symbolize moral superiority (Donini et al. 2013). The healthy life is the good life and striving for health is one of the most important goals in life. Therefore, a healthy life equates to a good life (Komduur et al. 2009).

Medical conclaves do their best to help members eliminate health risks. For example, life pattern designers instill in people the notion that they should do as the medical doctor says, i.e., a type of health counseling. Life pattern designers determine a lifestyle pattern to optimize both their client's health and their social assessment score by looking at information supplied by WatchMe (pp. 87-88). Interestingly, emergency rooms in Harmony's World are referred to as emergency morality centers (pp. 46-47). We argue that all aspects of life protection, medical care, and ethics are inseparable, and that healthy longevity equates to goodness in this world. Beyond maintaining complete health and extending life to the extent possible, there exists a desire for immortality.

In Harmony's World, citizens are required to live as resources to the community. Tuan explains this as follows:

Resource awareness. That was how people defined their obligation to society. That and the concept of a communal body. Always be aware that you are an irreplaceable resource, they would tell us. (p. 18).

With the population so dramatically reduced, our bodies are considered public property, valuable resources to society, and as such they were something to be protected, or so went the publicly correct thinking. (p. 32).

Medical conclaves obligate their members to live healthily as long as possible in order to maintain the community. This may be an inevitable consequence of the major disaster which happened half a century ago. But to live for society rather than oneself renders people merely a means to an end-they are objectified. Nonetheless, the majority of citizens are willing to fulfill their duty of being healthy and live as long as possible for the sake of their medical conclaves. In Harmony's World, one's body no longer belongs to oneself. Some people, especially children and adolescents, disagree with this awareness. For example, Miach as a high school student wanted a world where one's body was one's own. Tuan recalled that this was what Miach wanted. Miach wanted a body that was hers, not beholden to a society or its rules (p. 214).

Given that citizens are a public existence in Harmony's World, individual privacy no longer exists. Members of medical conclaves are required not only to keep themselves healthy at all costs, but also to continuously prove their own health to other members of the community. Private information such as name, age, occupation, and social assessment score, as well as current health status, must be discussed with other members of society (p. 93). In this lifeist society, where it was 
considered a moral obligation to reveal personal information, especially that concerning one's health, the very word "private" had the illicit stench of secrecy to it.

The regional ethics committee ("administration moral consortium") tracks members' assessment scores and discloses them to the public. Citizens are constantly evaluated and ranked based on their health. According to Tuan:

The augmented reality (AR) in my contacts kicks in. AR public metadata: Everything in our world had a user review attached to it. Even people had little social assessment stars stuck on them. (p. 56).

It can be argued that a healthy person is a person that you can trust and those who are not healthy seem to be the person who cannot be trusted. However, Miach suggests her friends that people are getting tired of this telling-everyone-whothey-are-all-the-time business. What a drag it is to have you to show you are healthy and you are taking care of yourself all the time (p. 95).

Finally, by fully pursuing health and longevity, as well as a medically optimal body, physical diversity is lost in society and the delusion of a "standardized" human body has become reality. The myth of a normalized human body was elevated to a high public standard (p. 227). Under the constant monitoring of WatchMe and advice from health consultants, obesity and emaciation were both driven out of the human experience (p. 59). All citizens live within the prescribed margins of a healthy adult. Regarding this, Tuan states:

They were all the same. Everyone. I realized how bizarre a sight the medically standardized Japanese populace presented. (p. 66).

Deviations from standard physique really stood out when everyone was listening so attentively to their health consultant's advice and following their perfectly designed lifestyle plans to the letter. The range of acceptable body types grew narrower every year. (p. 152).

The atmosphere of conformity that the society generated was too hard to break free of. (p. 153).

It is clear to us that Harmony's World would be intolerant of those who deviate from social standards in any respect. In addition, because of the similarity of Harmony's world we would like to refer to, one of the famous English utopian novels, Samuel Butler's Erewhon or over the range. This novel presents a society that values health above all else and punishes citizens who fall sick, blaming them for a moral failing. It seems that Erewhon's society is much more unsparing against unhealthy people than Harmony world (Butler 1872). In Erewhon, sick people are treated like criminals and they are stigmatized, fined, and imprisoned for a condition they could not help, whereas criminals are treated like sick people and they are helped, attended, and given decent treatments (Butler 1872; Osborn 1990; Jenkins 1983). In other words, the law of Erewhon outlaws physical rather than moral deviations, punishing disease and physical disability while treating acts of dishonesty and theft in the way that we would treat illnesses (Parrinder 2005). For an example a man in the last stage of tuberculosis being sentenced to life 
imprisonment. The rationale is that if harsh measures were not taken against disease, a time of universal dephysicalisation would ensue (Parrinder 2005; Bulter 1872).

The judge who assumes that the sick are responsible for their acts said to the patient in chronic respiratory failure with severe tuberculosis, "You may say that it is not your fault...If you tell me that you had no hand in your parentage and education and that it is therefore unjust to lay these things to your charge. You may say that it is your misfortune to be criminal; I answer that it is your crime to be unfortunate... Infliction of pain upon the weak and sicky was the only means of preventing weakness and sickness from spreading... You are a terrible and perilous character, and stand branded in the eyes of your fellow-countrymen with one of the maximum heinous recognized offences." The underlying rationale for self-responsibility for sickness seems to be based on the Erewhonians strange belief that an unborn child in Erewhon voluntarily choose to be born according to self-determination, even knowing very bad things could happen in their life. Therefore, individuals in the society are completely responsible for their health regardless of its causes or circumstances. Many ill individuals attempt to hide their disease in the society (Bulter 1872).

\section{Ethically Suspicious Measures Used to Achieve a World of Healthy Longevity}

In the previous sections, we introduced Harmony's World and brought to light various issues pertaining to health worship and the healthy longevity supreme principle, including the strong faith in medicine and healthcare, moralization of health issues, identification of health and good, people's obligation to be healthy, objectification of citizens, loss of privacy and diversity, and one's life designed by others (Table 1). All of these would be problematic from an ethical standpoint. This is because individual freedom would be deprived on many fronts. Moreover, Harmony's World is value-monistic, perfectionistic, and intolerant of lifestyles that are not perfectly healthy and diverse ways of thinking about healthcare. There are also other issues in this world. Below we discuss some of the ethically dubious means and policies that are used in Harmony's World to achieve health and longevity.

The first means by which Harmony's World achieves a perfect healthy utopia is the routinization and automation of healthcare delivery. The combination of WatchMe, Medicare, and Medicule have enabled the provision of instant, matter-ofmilliseconds, diagnosis and therapy, as well as prevention. Naturally there exists no room for self-determination and the concept of treatment refusal or informed refusal has disappeared completely. Every medical intervention has become a matter of course. All medical care procedures are quick and completely routinized.

Regarding issues with routinization, Japanese philosopher Kenji Hattori rightfully noted that routine examinations are often conducted implicitly without a sufficient explanation or with little expectation that they will be refused, and everyday medical care is being provided with such routine examinations as a matter of course. He also argued that the word "routine" or routinized healthcare system would deprive patients of their initiative in medical decision making by suggesting 
that all other people or patients would usually do the same thing. He concluded his criticism against routinization by noting that, whenever an action or intervention is intended to be routinized, we should ethically scrutinize potential problems caused by the routinization (Hattori 2001).

In Harmony's World, which effortlessly provides citizens with adequate and affordable medical care, the pressure to use it is stronger because no financial barrier exists. In our opinion, there likely is no option not to install WatchMe, not to set Medicare in one's house, or not to receive a diagnosis, prevention, and interventions through Medicule in medical conclaves. Harmony tells us that the medical conclaves are a gathering of people who have reached a consensus on a particular medical system (p. 34), but it is unclear to us the extent to which the consensus is voluntary or what members have actually consented to.

The second means by which Harmony's World achieves a perfect healthy utopia is through cryptic and clever techniques and covert interventions, including educating individuals to voluntarily internalize social norms, incentives tied to social assessment scores, domination by the atmosphere of society, and kind watching supported by affirmative paternalism. In this world, there is no unilateral and forced order to become healthy-no enforcement exists. Rather, people are skillfully driven toward the direction of health promotion. From childhood, they are repeatedly instructed and guided to suppress human instincts and impulsive desires which could result in an unhealthy state through polite education. The world has made them think that they themselves should voluntarily try to be and stay healthy. Society requires citizens to voluntarily internalize morality consistent with social norms (p. 236). Such a framework creates a contradiction within the individual; since it is not simple or high-pressure coercion, face-to-face rebellion and rejection are psychologically difficult. Miach notes:

I knew how barbaric people could be. And I knew how broken they could become when they tried to repress that nature. I thought that this society, admedistrative society, this lifeist system was all wrong. A society that wanted me to regulate myself internally, even while people were killing themselves all around me. It was just bizarre. (p. 236).

In our view, if you failed to internalize social norms which are long taught to be self-evidently good and right, you may feel guilty or have reduced self-esteem. You may also feel alienated from others who have naturally accepted these social norms. Freedom inside would be lost because you are expected to monitor yourself on your own initiative. To this, Miach further notes:

A society where rigid self-monitoring was the only path to peace and harmony. (p. 236).

One commentator states:

The everyday practices involved in improving or maintaining our own health - eating, exercising, feeling emotions, managing time, sleep, and so on - do not merely constitute our health; they also constitute our identities. The combination of obligations to internalize and act in accordance with shared moral 
norms and a focus on individual achievement seems likely to limit human freedoms. (Carter et al. 2011).

Not only educating people about social norms, but social assessment would also be an incentive to become healthy in Harmony's World. Careers and medical records are used to award social assessment points. In a world where you must always keep others informed of your health efforts and health condition, the majority of people may want to get as high a score as possible. Families and supervisors would also pressure people to do so. There is also psychological control by "the air" or atmosphere, rather than written laws or rules. The atmosphere of Harmony's World decides almost everything. Invisible rules that reflect common sense and "the air" are conceptually very Japanese. Regarding impressions about buildings in Japanese cities, Tuan mentions:

There weren't any laws against painting a building something more exciting, and yet here they were, an endless line of houses, all cast in bland, nondescript shades. None of them stood out against others. (p. 48).

In fact, there are no laws that prohibit drinking in most medical conclaves. One of Tian's WHO colleagues noted:

Funny thing is, it turns out that out of all the thousands of admedistrations in the world, only twenty-six have laws on the books actually prohibiting alcohol. Just twenty-six that forbid their members to imbibe. In all the rest, it's just not done. I am sure that that Social Assessment analysis has something to do with that. That is how the social assessment points work. As long as enough people agree about something, it starts being reflected in your points, and before you know it, you had better behave or else. And enforcement is built in. (pp. 220-221).

Good intentions and kindness make it difficult for people to counter or refute the World's health interventions. Harmony's World is not malicious. It is not a cold and cruel surveillance society, but rather a warm and kind watching society. It attempts to connect all people to its server from good will and kindness. Importantly, some citizens, like Miach's adoptive mother, are thankful. She mentions the following to Tuan:

My WatchMe (the public correctness monitoring module in it) just warned me my emotional state was beyond acceptance parameters for interfacing with others. It is a real lifesaver, having another pair of eyes inside me to help me through these things. (p. 103).

But Tuan felt that mankind was trapped in an endless hospital. (p. 49).

Informational regulation as an additional kindness is also notable. It serves as a paternalistic block on harmful information. Tuan notes that parts of their history have been censored, images in particular, such as horribly disfigured corpses, and that people need special clearance to see those. Even what had probably been considered tame content by the standards of yesteryear was teeming with violence by the peaceful, elegant standards of society (p. 18). Novels are no 
exception. Tuan indicates that any novel or essay people are about to read would be scanned in advance and cross-referenced with their therapy records (p. 60).

In the middle of the story, the perpetrator of a massive simultaneous suicide attempt sent a TV station a one-man-one-kill order. The newscaster who read the statement was killed on the air by the mysterious perpetrator. This killing scene was instantly censored by the AI censor. The image cut out and was replaced by other thing (p. 144). But how is the AI programmed? Perhaps information other than that which protects the individual is also censored, for example, the problems of medical conclaves. Information can be fabricated and falsified. Delivered contents could be biased in favor of the community. Information critical against authorities will probably be cut off. Totalitarian control of information is a substantial barrier to autonomous thought and independent decision-making.

The third means by which Harmony's World achieves a perfect healthy utopia is through inappropriate responses to issues. In Harmony's World, there are many suicide attempts and acts of self-harm, particularly among children and young people. Yuki Keita, an 85-year-old university professor who does brain research, told Tuan that the statistical rise in suicides is troubling and that pharmaceuticals and novel therapeutic treatments, as well as legal support for such treatments, would likely eventually bring these under control. He also noted that those who would want to destroy the safe and stable cycle of life are anathema to the rest of us (pp. 112-113). Tuan also pointed out that even without the mass simultaneous suicides, administration reports showed an increasing trend in suicide rates among youngsters. More kids were cutting their wrists, hanging themselves, and jumping off buildings (p. 181).

However, the cause of suicides among youngsters resides exactly in the very system of medical conclaves. In Harmony's World, many cannot bear to fit into the molds society stamps for them and, according to Tuan, the breakpoint of an over-considerate society is nearing (pp. 112-113). Souls in danger of being crushed by society were, in turn, gnawing away at its underbelly. There are souls that just did not fit, soul of children yearning for disease, for damage, for pain are predominant (p. 180). With wickedness in their hearts, they tried to ruin their own precious lives, and they knew what they were doing. Tuan thought that something had to be wrong with this picture and even in her brainwashed society people had begun to realize it (pp. 180-181). A boy who committed suicide said he hated this world and did not belong to the world (p. 236).

We argue that the high suicide rate in Harmony's World is clearly a serious side effect brought about by its social institutions, healthism, super-medicine, and lack of freedom and diversity. One could argue that it is in fact medical conclaves that require emergent intervention and correction, rather than the young wouldbe-suicidal. Nevertheless, the leaders of the Next-Generation Human Behavior Monitoring Group carried out the "Harmony project" without resolving the true causes. Tuan's father, who is a brain scientist, explains the "Harmony project" as follows (p. 181):

In controlling the feedback web in the midbrain with medicules, we found we were able to influence human decisions, emotions, and thoughts. The 
control of human will was a hot topic with upper leader at WHO and some of the admedistrations. (p. 177).

In those days, we picked up a lot of kids like her (Miach) and put them into treatment. We gathered the ones that wanted to kill themselves, especially the ones who overate or refuses to eat, the ones who wanted to watch themselves grow weak and die. Our goal was to create a harmonized will inside the human brain. We call it the "Harmony program." There were plenty of kids back then who had attempted suicide more than once, just as there were plenty of them now. (p. 181).

Because their system of values is fashioned to be in perfect harmony with society, there are far fewer suicides, and the kinds of stress we find in our admedistrative society disappear completely. (p. 184).

To Tuan, it appeared as though her father and his colleagues of the Next-Generation Human Behavior Monitoring Group were trying to create a self-evident person, perfectly adapted to the stresses of the administrative society (p. 183). Because the correctness of society is self-evident to the leaders, they attempted to alter the values of young people by manipulating their brains. In our view, this is unilateral brainwashing and cannot be ethically justified-the "Harmony project" is a typical example of an unethical human experiment.

As mentioned above, Harmony's World makes it self-evident that health longevity has the highest value and that all members have an ethical obligation to maintain healthy longevity and world peace. The rightness of the object of strong faith would of course be self-evident and an absolute right to believers. Those who believe there is self-evident truth would rarely reflect on the justification of the very truth. There is no room for doubt or reflection on the truth. For the sake of respecting self-evident truth, self-evident persons may consider it justified to physically manipulate the brain and alter the consciousness and thoughts of young individuals who cannot accept social norms. We argue that the "Harmony program" is a future-world lobotomy. Instead of dealing with the real cause that is disturbing and confusing the mind, lobotomy destroys the brains of the mentally ill.

\section{Discussions on Relevant SF Works}

Before concluding our paper, we present four SF works that are deeply relevant to our discussion of Harmony's World, and touch on their contemporary significance in comparison with that of Harmony's World. Since it is beyond the scope of this paper to introduce in detail the contents of these works, we will mainly focus on backgrounds and events described in each work. These include mental therapy by means of nanotechnology, environmental manipulation, and ultimate harm to Japanese society.

The first two of the four is a duology, Queen of Angels (1990) and Slant (1997), written by American SF writer Greg Bear (Bear 1990, 1997). In the world of Queen of Angels and Slant, nanotechnology has been perfected, and humans are given the ability to change their environment and themselves at a cellular level, 
as well as to achieve perfect mental health. In Los Angels, the setting of Queen of Angels, 65\% of people are receiving psychiatric treatment by 'nano therapy,' a literal brain reconstruction in which tiny surgical prochines are used to alter neural pathways. Nano therapy is performed to repair genetic defects and improve work, sociality, and human relationships, and to correct the behavior of criminals. In other words, the society has reached a point where effective therapy is a necessity. People are even subjected to permanent mood adjustment. The world depicted in these books is fundamentally different from Harmony's World, in that no direct interventions to the mind or brain are generally performed in the latter.

Nanotechnology is used not only in psychotherapy but also to transform, heal, and strengthen the body. With this technology, police officers can regenerate their severely damaged bodies many times. At the same time, their wounds and diseases are instantly fixed from inside the body using medical monitors and stabilizer infusions. Indeed, nanotechnology has realized an 'in-body hospital,' and in this aspect, similarities can be found with Harmony's World.

Murderers are given 'enforced deep therapy,' a therapy that fixes and changes them. Personality correction is mandatory for all criminals, resulting in a sharp decline in crime with almost zero murder cases. This therapy is similar to the Harmony project in Harmony's World. The latter, however, is only used as a last resort for social survival due to its side effects (i.e., deprivation of consciousness).

In the world of Queen of Angels and Slant, discrimination and economic disparities emerge between those who receive nano therapy and those who do not. Contrarily, Harmony's World is free of conflict and disparities. In Slant, it becomes apparent that mental therapy based on nanotechnology is ineffective, and difficult-to-treat cases in which individuals repeat anti-social behaviors ("core therapy reject," often with a long criminal history) or experience relapse and worsening of conditions ("fall-out") start to appear.

The Harmony project in Harmony's World would have been implemented to treat suicidal people as planned, had it been successful, and perhaps, its use would have been extended to people with mild mental ailments and mood disorders. If no one followed the one-man-one-kill order in Harmony's World, and had the Harmony project been successful as mental therapy with no side effects, a peaceful, equal 'Slant' might have been realized. As described above, nanotechnology depicted in the duology has been used in the real world for treating various physical illnesses. In the near future, it may be applied to the brain, leading to the establishment of nextgeneration psychiatric surgery.

The third story we introduce, from the perspective of quasi-forced environmental manipulation for the purpose of health promotion, is "Ai no Seikatsu (Life of Love) (Hayashi 2017)." It is a part of a collection of short stories on the theme of "creating the future," published by the Japanese Society for Artificial Intelligence with the cooperation of Science Fiction and Fantasy Writers of Japan. The main character is an obese, diabetic male writer. His cohabitating girlfriend left him, as she ran out of patience due to his sloppy and irregular lifestyle. He ended up renting a furnished apartment with home appliances in a brand-new building. However, strange things start to happen in this apartment: in the morning, the curtains open automatically and coffee is made; at $11 \mathrm{pm}$, room lights automatically turn off. When he tries to have a bowl of rice with 
curry and pork cutlet for breakfast at a restaurant, his smartphone all of a sudden sends a message, "Stop!" He can only buy healthy food with his smartphone payment app. The writer loses weight without even knowing it, and his physical condition improves. He begins to lead a regular life. The story ends with his illness getting better, and his work being a success. As it turns out, a woman had built a self-learning system that combines AI, IOT, and ICT in order to improve her former roommate's lifestyle habits. This system was manipulating the furniture and household electronics, as well as the writer's smartphone.

The main character of this story loses weight and becomes successful and happy. The theme here is how AI embedded in our living environment can change our lives and values without us knowing. It is a world in which people are manipulated into selecting a healthy choice unknowingly. People are constantly monitored, warned if their health condition is poor, and are restricted in terms of access to unhealthy food and products. It is a miniature version of Harmony's World, in which the healthier people are, the higher their social assessment score. All is well and good, but we are left with a complex feeling about the clever manipulation, as in the case of Harmony's World. The manipulation toward a healthy lifestyle depicted in this story has already begun around the world, as with the above-mentioned Japanese Health Promotion Act (2002) (Okita, enzo, Asai 2017).

Lastly, "AI Houkai (AI collapse)" by Rintaro Hamaguchi depicts the collapse of Japanese society, i.e., a crisis of ultimate harm, caused by the malfunctioning of medical AI (Hamaguchi 2019). In 2030, Japanese society is completely reliant on a medical AI called Nozomi ('hope' in Japanese), which has deep learning and self-learning abilities, to carry out medical examination, vital sign monitoring, data management, and physical condition management. Roughly $90 \%$ of all Japanese medical institutions have introduced Nozomi in inpatient practice. Patients who visit these institutions send their physical data to Nozomi from their wearable devices on a regular basis, and Nozomi administers insulin, provides instructions on medication, or controls cardiac pacemakers. Moreover, infrastructures related to everyday life such as finance, security, and transportation are also single-handedly managed by this AI. One day, a terrorist hacks Nozomi, and Nozomi suddenly starts killing patients. The medical AI with the power to decide life and death, now running out of control, brings about a crisis of collapse in Japanese society.

The terrorist attempts to kill all incompetent people, those who cannot work, and those with low productivity—i.e., the sick, disabled, and elderly—with the aim of rejuvenating Japan's super-aged society and creating a society with high economic power and no poverty via the selection of life. This story portrays the horror of AI malfunctioning, and the crisis of ultimate harm brought about by one individual. It would not be strange for something similar to happen in the future. Whatever the cause, if WatchMe's sensor, its network, or medicare which synthesizes Medicule falls out of order, a similar crisis would easily fall upon Harmony's World. 


\section{Conclusion: Should We Aim to Create a Perfect Healthy Utopia?}

Harmony's World aimed to establish a perfect healthy utopia and nearly completely realized this goal. We believe the creation of the world depicted in Harmony to be a great work when considered solely from the standpoints of medical science and healthcare. Intuitively, the healthier we are and the longer we live, the better. However, from an ethical standpoint, it is clear that there are serious issues with the medical conclave system and unacceptable measures taken to maintain it (Table 1). We argue that the existence of Harmony's World cannot be accepted as is. We oppose the basic idea of creating a super-healthy society at the expense of all other worthy things, in particular, our freedom, diversity, and privacy. We need to remain a free and diverse existence with the ability to make decisions about one's own life without interference. We do not want to be monitored by a watchful society, even if the intentions are good and ultimately would make us healthier.

In Harmony's World, even decisions about lifestyle are outsourced. Any decision must always be made together with others, and thus it is no longer possible to live according to one's idiosyncratic ways. Tuan says,

We are expected to always keep personal information on display, to participate in admedistration discussions on morality sessions, and to make decisions only after receiving advice from the appropriate expert. (p. 137).

She feels that people in administrations prefer that other people decide things for them (p. 147). However, in the real world, there are things which we cannot help but decide by ourselves. In Harmony, a perfect example of this is the response to the one-man-one-kill declaration. Regarding this order, Tuan was disgusted with the society that calls for people to gather and talk about the situation.

Most admedistrations had called immediate sessions to discuss the declaration, but hardly anyone had shown up. What was there to discuss? This was not something you could discuss in public. This was a decision everyone had to make on their own. (p. 152).

Thinking alone and deciding alone is sometimes important, and we should not lose the ability and will to make decisions on our own without support from others, even if it is difficult to do so.

We need not be perfect. There is no end to the pursuit of perfection concerning health and longevity in our life because there is no such thing as an objectively "long enough" life-span, and because the occurrence of diseases and disorders is best kept as close to zero as possible. The higher the quality of life, the better. The lower the individual out-of-pocket payments, the better. Healthcare is the subject of infinite craving. Health needs and desires are virtually limitless (Asai et al. 2017; Beauchamp and Childress 2013). Thus, the pursuit of medical perfection will inevitably end in vain and ruin our satisfaction, acceptance, and peace of mind. Social solidarity is important and good, but we argue it is not something we should aim for from the beginning. On the contrary, it is something we achieve naturally and unintentionally as a result of our activities and relations with others. Medicine and ethics 
are different, and health and good are not identical. There is no self-evident truth in our lives. Although being healthy is obviously good, health should not be regarded as the only good in our lives. The monistic claim that health has the sole highest value is unacceptable to us pluralists.

We consider the infinite craving for health and healthcare problematic, but survival is a more powerful craving by human nature. Naturally, some people think they are better off staying alive even in poor health rather than having to face ultimate harm, i.e., the extinction of mankind. However, the validity of this claim depends on the context of poor health. For example, Persson \& Savulescu argued the following in their discussion of ultimate harm: "Something could be ultimately harmful by forever extinguishing sentient life, or by damaging its conditions so drastically that, in general, life will not henceforth be worth living (Persson and Savulescu 2012)." Therefore, we need to consider what an acceptable condition would be in which we would want to keep living.

Would people want to live even if in a vegetative state, or as perhaps even a robot or zombie? The answer will be different for each individual. Some may not want to keep living if their condition is such that it meets the requirements for euthanasia (e.g., unbearable pain with no prospect to recover), which is practiced in the Netherlands and elsewhere. However, others might not feel the same way. With the presence of a loving family, a purpose in life, and valuable memories, some people may wish to live under any physical condition. Yet, for those of us who live outside the religious culture of a monotheistic personal God, it is somewhat unrealistic to think that life in any condition is a gift of God and should thus be better lived than lost. We do not understand, frankly, the meaning of "reason for being" in a state of the eternal absence of "self," self-consciousness, and free will, which is realized in the ending of Harmony.

It can be argued that quality of life studies, by shifting away from ends-oriented criteria such as survival rate and life expectancy and towards subjective psychometrics including our purpose and meaning of life, they propose that a patient's quality of life must be determined in relation to his or her affective preferences and would agree with our position. They translate both the medical condition affecting survival and the affective response to that condition into a common register of temporal progression: QALYs. However, the body's physical well-being, i.e. survival or length of life, is taken into account only to the extent that it impacts the patient's affective experience of the time period under consideration (Eatough 2011). We would argue that our perception concerning our life strongly rely on the purpose and meaning of our lives to provide us with a sense of self-worth and that our sense of self-worth would naturally have a tremendous impact on our subjective estimation of quality of life, which is sometime more important than the length of life.

We do not deny the great value of a healthy longevity society. Naturally, we do not want to live in a world ridden with disease, disability, pain, premature death, and separation. What is needed is a world where people are adequately healthy, while avoiding harmful health worship and healthism. How can we achieve this? In our view, the answer is provided early on in Harmony. The answer is "Do everything in moderation." A warrior of the Tuareg, one of the characters in the tribe that does not belong to any medical conclave, suggests this. He referred to Tuan 
and her colleagues as "medicine people." Below is a conversation between the warrior and Tuan.

Tuan You think we bow too deeply to our gods, then?

Warrior In a word, yes. 'All things in moderation' you say, but you do not practice it. You are so filled with your faith that you must push it upon us as well.

Tuan We moderates are in the minority. (pp. 28-30).

Finally, in Harmony, the top leaders of The Next-Gen Human Behavior Monitoring Group faced a chaotic situation in which murders and suicides among citizens became frequent after the perpetrator's declaration. They were frightened of chaos, frightened of people losing their rational minds, and frightened of riots that would lead to genocide and nukes going off all over the world again. (p. 177) As a consequence, they destroyed the consciousness of all members of medical conclaves, including themselves and Tuan, in order to conserve the medical conclaves. In a nutshell, Harmony tells us a story in which individual consciousness was deprived forever for the sake of preserving the healthy longevity society. To us, the ending suggests that we human beings should not have individual consciousness, self-consciousness, or "I" if we hope to maintain a healthy and peaceful society.

We are ambivalent about the story's ending. Certainly, if unhealthy foods have disappeared and a medically ideal life plan is presented and exactly followed, then we would be healthier as a group and live longer. Those who are self-aware and think freely with different interests and value systems are likely to have conflicts with others and disobey medically appropriate health advice. We are also willing to admit that there are many unhealthy people who are "prematurely dead" from inappropriate lifestyles and addictions to smoking or alcohol. If this is the case, we should not simply dismiss Harmony's message as completely nonsensical or fictional. Nonetheless, we cannot accept Harmony's ending, because a free and autonomous agent must not be used solely for any purpose. Harmony's World wrongly defines good, or being ethical, as being healthy in a very monistic way. We argue that it is ethically sufficient for us to live moderately healthily and happily, so long as we remain self-aware, self-conscious, and unique. Even if society needs to preserve its values, it is wrong to destroy individual consciousness.

A commentator who discusses Aldous Huxley's two novels argued the danger of forgetting that, in our world, complete control is impossible and that it is even more dangerous to forget why we should be happy that this is so. He added that our world is pluralistic and people hold vastly different views on what a good life entails and that a peaceful pluralism is impossible (Schermer 2007). In conclusion, we argue that we can lead a reasonably healthy and long life in a peaceful world, so long as everything is done in moderation, we pay some attention to our health, and we are considerate to others in accordance with the no harm principle. However, our self-awareness and consciousness could lead to an unhealthy life and premature death, which otherwise could be preventable. We would rather accept the consequences than lose our free will and self-aware consciousness. 
Another point to note is that the extent to which social control over individuals is considered acceptable changes depending on whether or not the actions of individuals have the potential to harm others. Naturally, enhanced social interventions are justified if an act causes direct harm to others, or relates to murder or terrorism. But as argued above, if people have compassion for others and act in accordance with the no harm principle, the potential for ultimate harm could be reduced. Our argument is not directed at nuclear weapons or bioterrorism; it is primarily a criticism of excessive health management. Just because a certain number of people are unhealthy, it does not mean the whole world would collapse (although healthcare costs would be high). Those who follow their own life philosophy and avoid strict health management would have to take responsibility for the consequences of their behavior. Healthcare systems could be modified in such a way that, if those individuals get sick due to their own carelessness, they can get treated at their own expense. However, it should be noted that to take a stance that all diseases are to be considered an individual's responsibility overlooks one's upbringing, peer pressure, genetic predisposition, and luck as significant influencing factors.

On the other hand, people with highly pathogenic infectious diseases, such as COVID-19, have the potential to harm others. Thus, their isolation is warranted, and the restriction and monitoring of their behaviors as long as they remain infectious cannot be avoided. Yet, such requirements must be kept to the necessary minimum, and human rights and social defense must always be balanced. That said, we are not advocating that each person is free to do anythig in any way they desire. We maintain that everything should be done in moderation, and that we should pay attention to our health and be considerate to others in accordance with the no harm principle.

We value 'moderation,' which we consider a moral virtue. If many people embodied this virtue, our world would be a better place. We anticipate also that the likelihood of ultimate harm would decrease. According to the Analects of Confucius, a classic of Eastern philosophy, "There is little to choose between overshooting the mark and falling short," and "Supreme indeed is the Mean as a moral virtue. It has been rare among the common people for quite a long time." These ideas are the basis of the 'everything-in-moderation' principle we advocate (Confucius 1993).

Some argue that human beings lack sufficient altruism, empathy for the suffering of others, and a sense of justice, and that it is difficult to cultivate those with conventional methods of education (Persson and Savulescu 2012). Unfortunately, we cannot completely deny that assertion. Perhaps humans are morally imperfect and our brains cannot stop us from harming others. That said, is it permissible to perform a lobotomy on a person's brain or perform medical interventions aimed at improving morals? Or, as in the case of Harmony's World, to take away self-consciousness permanently from people? At this time, we cannot agree with these. Furthermore, we think that the rights and wrongs of permanently depriving consciousness from people should be determined at least by democratic means, and not by a handful of people.

Acknowledgements Our paper has been writing under the support of Human Information Technology Ecosystem (HITE). HITE is a research and development (R\&D) focus area delivered by the Research Institute of Science and Technology for Society (RISTEX), Japan Science and Technology Agency (JST). 


\section{Compliance With Ethical Standards}

Conflict of interest The authors declare that they have no conflict of interest.

\section{References}

Asai, A., Okita, T., Enzo, A., Ohnishi, M., \& Bito, S. (2019). Hope for the best and prepare for the worst: Ethical concerns related to the introduction of healthcare artificial intelligence. Eubios Journal of Asian and International Bioethics., 29, 64-71.

Asai, A., Okita, T., Tanaka, M., \& Kadooka, Y. (2017). A critical discussion of arguments against the introduction of a two-tier healthcare system in Japan. Asian Bioethics Review, 9, 171-181. https:// doi.org/10.1007/s41649-017-0023-y

Bear, G. (1990). Queen of Angels. New York: Open Road Integrated Media.

Bear, G. (1997). Slant. New York: An Orb Book.

Beauchamp, T. L., \& Childress, J. F. (2013). Principles of Biomedical Ethics (7th ed.). Oxford University Press: Oxford .

Biesen, W. V., Decruyenaere, J., Sideri, K., Cockbain, C., \& Sterckx, S. (2019). Remote digital monitoring of medication intake: Methodological, medical, ethical, legal reflections. International Journal of Clinical and Laboratory medicine. https://doi.org/10.1080/17843286.2019.1708152

Butler, S. (1872). Erewhon or over the range. London: Trübner \& Co.

Carter, S. M., Entwistle, V. A., McCaffery, K., \& Rychetnik, L. (2011). Shared health governance: The potential danger of oppressive "Healthism." The American Journal of Bioethics, 11(7), 57-59.

Confucius. . (1993). The analects, translated by Raymond Dawson. Oxford University Press: Oxford.

Donini, L. M., Marsili, D., Graziani, M. P., Imbriale, M., \& Cannella, C. (2013). Orthorexia nervosa: A preliminary study with a proposal for an attempt to an attempt to measure the dimension of the phenomenon. Eating and Weight Disorders, 9, 151-157.

Eatough, E. (2011). The time that remains: Organ donation, temporal duration, and bildung in kuzuo Ishiguro's never let me go. Literature and Medicine, 29, 132-160.

Hanaguchi, R. (2019). AI hokai. Tokyo: Kodansha-Bunko. ((In Japanese)).

Hayashi, J. (2017). AI no Seikatsu: AI's dreams (AI no miru yume ha). Bungei-Shunshu Tokyo (In Japan)

Itai, S. (2019). Development of novel functional formulations based on pharmaceutical technologies. Yakugaku Zasshi, 139, 419-435.

Jenkins, P. E. (1983). A manifesto of the rehabilitative ideal. Journal of Criminal Justice, 11(1), 35-46.

Johnston, J., Lantos, J. D., Goldenberg, A., Chen, F., Parens, E., Koenig, B. A., et al. (2018). Sequencing newborns: A call for nuanced use of genomic technologies. Hastings Center Report, 48(2), S2-S6.

Kanaya Y, Ichikawa M 2018 Healthcare service in super-smart society (Society 5.0) In Nishimura S (Ed.), Healthcare white paper 2017-8, (p. 37) Nippon Iryo Kisaku Tokyo (In Japanese)

King, N. M. P., \& Bishop, C. E. (2019). How should physicians help patients understand unknowns of nanoparticle-based medicines? AMA Journal of Ethics, 21, 337-346.

Kirinuki-Sokuho. (2019). Possibilities of AI, Health and safety (Ed.), A collection of newspaper articles, (pp. 7-23), Nihon/Mic Ltd: Osaka.

Kobayashi, M. (2007). What is genome editing? Kodan-sha Tokyo.

Komduur, R. H., Korthals, M., \& Molder, H. (2009). The good life: Living for health and life without risks? On a prominent script of nutrigenomics. British Journal of Nutrition, 101, 307-316.

Martin, D. H., Hauser, J. B., \& S. L. , et al. (2018). Approach to the patient with neurologic disease. In J. L. Jameson, D. L. Kasper, \& D. L. Long (Eds.), Harrison's principles of internal medicine $20^{\text {th }}$ (p. 3027). New York: McGraw-Hill Education.

Martani, A., Geneviève, L. D., Poppe, C., Casonato, C., \& Wangmo, T. (2020). Digital pills: A scoping review of the empirical literature and analysis of the ethical aspects. BMC Medical Ethics, 21(1), 1-13. https://doi.org/10.1186/s12910-019-0443-1

McCartney, M. (2016). Clean eating and the cult of healthism. British Medical Journal, 354, 4905.

Ohta M (2018) A disease as art, Heal as a game-reading harmony a decade later March 20, 2018, https ://school.genron.co.jp/works/critics/2017/students/lemdi04/2821/.

Okita, T. E., \& A., Asai, A. . (2017). Reexamination of the concept of 'health promotion' through a critique of the japanese health promotion policy. Public Health Ethics, 10, 267-275. 
Osborn, D. (1990). Samuel Butler's Erewhon as social psychology. Teaching of Psychology, 17, 115-117.

Parrinder, P. (2005). Entering dystopia, entering "Erewhon." Critical Survey, 17, 6-21. https://doi. org/10.2307/41556091

Persson, I., \& Savulescu, J. (2012). Unfit for the future: The need for moral enhancement. New York: Oxford University Press.

Schermer, M. H. N. (2007). Brave new world versus Island -Utopian and Dystopian views on psychopharmacology. Medicine, Health Care and Philosophy, 10, 119-128.

Sekai Sekai Cyoukan, The economist, Nikkei Business March 5, 2020, https://business.nikkei.com/atcl/ NBD/19/world/00187/.

Sunshine, J. C., \& Paller, A. S. (2019). What nanobasics should be taught in medical school? AMA Journal of Ethics, 21, 337-346.

Susskind, R., \& Susskind, D. (2015). The Future of the professions: How technology will transform the work of human experts. New York: Oxford University Press.

Publisher's Note Springer Nature remains neutral with regard to jurisdictional claims in published maps and institutional affiliations.

\section{Affiliations}

\section{Atsushi Asai $^{1} \mathbb{D} \cdot$ Taketoshi Okita $^{1} \cdot$ Motoki Ohnishi $^{2} \cdot$ Seiji Bito $^{3}$}

1 Department of Medical Ethics, Tohoku University Graduate School of Medicine, 2-1 Seiryo, Aoba-ku, Sendai, Miyagi 980-8575, Japan

2 Department of Health and Welfare Public Policy, Laboratory of Public Health, Aomori University of Health and Welfare Graduate School of Health Science, 58-1 oaza hamadate aza mase Aomori, Aomori 030-8505, Japan

3 Division of Clinical Epidemiology, National Tokyo Medical Center, National Hospital Organization, 2-5-1 Higashigaoka, Meguro-ku, Tokyo 152-8621, Japan 